\title{
Customer Participation in Service Recovery:
}

\section{A Meta-Analysis}

\author{
Yves VAN VAERENBERGH
}

KU Leuven

\author{
Simon HAZÉE \\ HEC Liege - University of Liège
}

Annelies COSTERS

KU Leuven

Accepted for publication in Marketing Letters

Send correspondence to Yves Van Vaerenbergh (Corresponding author): Department of Marketing, KU Leuven, Warmoesberg 26, 1000 Brussels, Belgium

(Yves.VanVaerenbergh@,kuleuven.be; Phone: +32 260982 89)

Simon Hazée: Department of Marketing, HEC Liège, University of Liège, Rue Louvrex, 14, 4000 Liège, Belgium, (Simon.Hazee@uliege.be, Phone: +32 423272 25).

Annelies Costers: Department of Marketing, KU Leuven, Warmoesberg 26, 1000 Brussels, Belgium (Annelies.Costers@kuleuven.be; Phone: +32 230022 30)

Acknowledgements:

The first author (G0C5617N) and third author (SB/151556) are grateful for financial support from the Research Foundation - Flanders. 


\begin{abstract}
Research on customer participation in service recovery is surging, yet empirical examinations provide mixed results. A meta-analysis of 30 independent samples reported in 21 studies $(\mathrm{N}=7,872)$ shows that the effect sizes for the relationships between customer participation in service recovery and customer outcomes are rather weak. We also find that customer participation in service recovery has an indirect effect on satisfaction with service recovery via distributive justice and procedural justice, but not via interactional justice. Conversely, customer participation in service recovery has an indirect effect on overall satisfaction via distributive justice and interactional justice, but not via procedural justice. Finally, the effectiveness of customer participation in service recovery is stronger when customers participate in the outcome of the recovery, when additional compensation is offered, for customers with an Eastern cultural background, and in online settings.
\end{abstract}

Keywords: service failure; service recovery; customer participation; co-creation; customer complaints 


\section{Customer Participation in Service Recovery:}

\section{A Meta-Analysis}

\section{INTRODUCTION}

Customer complaints represent a critical moment of truth in the firm-customer relationship. An unsatisfactory response to the customer's complaints may fuel customers' decision to leave (Knox and Van Oest 2014) and even to retaliate against the firm (Joireman et al. 2013). Researchers show that by resolving the problem or offering compensation, apologizing for the failure and acting quickly, can help restore customer outcomes (e.g. Gelbrich and Roschk 2011). Researchers have begun to disentangle the customer's role in the service recovery process. A growing body of research examines the effects of customer participation in service recovery, defined as customers' ability to "shape or personalize the content of the service recovery through joint collaboration with the service provider” (Roggeveen et al. 2012, p. 772). For example, customers who had their flight cancelled may go through different alternative solutions together with the desk employee and finally choose which alternative suits them best.

Although prior studies provide useful insights regarding the effectiveness of customer participation in service recovery, further research is necessary because of three main reasons. First, the empirical findings regarding the effectiveness of customer participation in service recovery are, at best, mixed. Some studies indeed show customers react favorably to participation in a service recovery (e.g., Dong et al. 2008; Roggeveen et al. 2012), whereas other studies show considerable variation in terms of magnitude and significance of the effects of customer participation in service recovery on customer outcomes (e.g., Hazée et al. 2017; Heidenreich et al. 2015). These findings create doubt about the absolute strength and significance of these relationships. Secondly, researchers used a wide variety of dependent variables in their studies (e.g., Balaji et al. 2018; Dong et al. 2016). Yet no study demonstrates 
their relative effectiveness or conjointly analyzes the full range of relationships in an overall model. The third reason is that prior research lacks empirical consistency in its theoretical underpinning. While most studies draw on justice theory as a theoretical anchor for understanding the effectiveness of customer participation in service recovery, some argue customer participation is related to one specific justice dimension (e.g., Karande et al. 2007) whereas others argue customer participation is related to all three justice dimensions (e.g., Gohary et al. 2016a).

The overall aim of the present study is to conduct a meta-analysis of the customer participation in service recovery literature. We attempt to answer the following research questions: (1) Is customer participation in service recovery positively and significantly related to customer outcomes? If so, what is the relative importance of customer participation in service recovery in driving these customer outcomes? (2) Which justice dimension underlies the effect of customer participation on customer outcomes? and (3) Do substantive and methodological moderators affect the strength of relationships between customer participation in service recovery and customer outcomes? In answering these research questions, we engage with Hazée et al.'s (2017, p. 107) observation that research needs "to further validate the relationships between a co-created recovery and customer outcomes, and to test moderators that might explain the mixed findings."

\section{CONCEPTUAL BACKGROUND}

\subsection{Effectiveness of customer participation in service recovery}

Firms have traditionally considered customers as passive recipients of their practices (Payne et al. 2008). This view has also been prevalent in prior research on service recovery, which is viewed as the actions taken by the firm for the customer following a service failure (Grönroos 1988). A new marketing logic sees customers as active rather than passive and value creation as a process in which the firm's and the customer's resources are integrated (Vargo and Lusch 
2016). This logic has been increasingly embraced by both practitioners and marketing researchers (Dong and Sivakumar 2017), who also started to explore the effectiveness of customer participation in service recovery.

Researchers have used a wide variety of outcome variables to examine this issue. As to compare with prior meta-analyses examining the effects of service recovery practices on customer outcomes (Gelbrich and Roschk 2011; Orsingher et al. 2010), this research focuses on customer satisfaction with recovery, overall satisfaction, as well as repurchase and wordof-mouth intentions as dependent variables. Orsingher et al. (2010) suggest future research should indeed focus on these specific dependent variables and consider them separately as they produce different effects. We also consider the three justice dimensions-distributive, interactional, and procedural — as distinct variables in this meta-analysis as justice is best conceptualized as a multidimensional construct (Orsingher et al. 2010). The conceptual framework in Figure 1 displays the variables and relationships that are examined in this metaanalysis. The nomological placement of each variable reflects the causal ordering of variables in Gelbrich and Roschk’s (2011) meta-analysis.

[Figure 1 here]

\subsection{Moderator variables}

We consider several moderator variables to gain insights into the mixed findings reported in prior literature, namely: type of service failure, type of customer participation in service recovery, whether additional compensation was offered, culture, and study context. We also added three control variables, namely: study design, sampling frame, and journal quality.

Type of service failure. Prior research distinguishes between process failures and outcome failures (Smith et al. 1999). Process failures occur when the service delivery is deficient in some way (e.g., a desk employee being impolite); in outcome failures the core service is not delivered correctly (e.g., a flight is cancelled). Customers can more easily determine the cause 
for process failures than for outcome failures (Chan et al. 2007), hence customers may have less need for extensive interactions with employees to find solutions to complaints about process failures. We expect that effect sizes will be lower in studies examining process failures than in studies examining outcome failures.

Type of customer participation in service recovery. Customers can participate during multiple stages of the recovery (Dong and Sivakumar 2017). Customers may collaborate with service employees and participate in either the recovery process (e.g., a customer exchanging information and looking at different alternatives together with the employee; Roggeveen et al. 2012), the recovery outcome (e.g., a customer selecting the alternative that s/he likes best; Karande et al. 2007), or both. Customers who can select a specific recovery solution are more likely to attain an outcome that is tailored to their needs, compared with customers who can only personalize the recovery process. This higher likelihood of obtaining the most appropriate outcome in turn would create more favorable perceptions of the recovery encounter (Hazée et al. 2017). We expect that effect sizes will be lower in studies where customers can only participate in the recovery process than in studies where customers can (also) select the recovery outcome.

Additional compensation efforts. Empirical research on customer participation in service recovery can be divided into studies where the researchers only examine customer participation versus studies where the researchers examine customer participation in conjunction with a compensation (albeit a monetary compensation or a psychological compensation in the form of an apology). If respondents must rely on multiple cues when evaluating products and services, then the effect of a specific cue on customer evaluations tends to be lower than when respondents must evaluate a single cue (e.g., Völckner and Hofmann 2007). We expect that effect sizes will be lower in studies where consumers receive additional monetary or 
psychological compensation next to customer participation in service recovery than in studies where consumers only participate in the service recovery.

Culture refers to "the collective programming of the mind, which distinguishes the members of one group of people from others" (Hofstede 2001, p. 9). In line with previous service recovery research (e.g. Sengupta et al. 2018), this moderating variable captures whether data were collected in an Eastern or a Western country. People living in Eastern cultures typically value interdependence and tend to focus more on relationships and connectedness than Western customers (Hofstede 2001). They have a stronger desire to cooperate with others in their environment than Western customers (Sharma 2010). For these reasons, we expect lower effect sizes for studies conducted in Western consumers than for studies conducted in Eastern countries.

Study context refers to whether the study was conducted in an offline or an online context. Prior research shows customers in an online setting perceive more control over the service delivery (Rust and Lemon 2001) as well as over how to respond to service failures (Chang and Chin 2011) compared to customers in an offline setting. Hence, customers in an offline setting might be more appreciative of receiving control over the recovery outcome (through participation in the recovery, see Guo et al. 2016) compared to customers in an online setting. We expect lower effect sizes for online settings than for offline settings.

We added three control variables. Study design captures whether researchers used an experimental design or a survey. Because experimental designs permit more control over potential confounding factors, experiments may produce stronger effect sizes than surveys (Farley et al. 1995). Sampling frame captures whether the researchers used a nonstudent or a student sample to test their hypotheses. Although researchers often use students as respondents to study customer participation in service recovery, they have more limited consumption experiences and different cognitive structures, leading them to weight experiences differently 
(Burnett and Dune 1986). Results from student samples may differ, in terms of both magnitude and direction, from results from non-student samples (Peterson and Merunka 2014). Finally, journal quality captures whether a paper is published in an elite journal or not. Authors may be more likely to submit strong and clear-cut results to elite journals, and editors and reviewers from elite journals may favor studies with strong and clear-cut results over studies with weak and ambiguous results (Murtaugh 2002). Given this observation, studies published in elite journals may report stronger effect sizes than studies published in non-elite journals.

\section{METHODS}

\subsection{Literature search and coding procedure}

Following established procedures, we identified papers examining customer participation in service recovery by means of a computerized bibliographic search in relevant databases $\left(\right.$ WebofKnowledge $^{\circledR}$, ScienceDirect ${ }^{\circledR}$, SpringerLink ${ }^{\circledR}$, Google Scholar ${ }^{\circledR}$ ). We searched for articles using the keywords "customer participation", "co-production", "co-creation", "customer involvement" and "recovery voice" combined with the keywords "service recovery", "complaint management" and "complaint handling". We supplemented this search with a manual search of references of key articles. The literature search covered the period from 2007 to March 2018 and generated 27 articles. Six articles were excluded from the analysis because (1) they were conceptual papers, (2) they focus on a co-created service failure instead of customer participation in a recovery, or (3) they did not present a control group which allows for testing the net effect of customer participation in recovery.

The remaining 21 articles were coded for the effect sizes and moderator variables. The correlation coefficient was selected as effect size metric; higher coefficient values indicate stronger effects of customer participation in service recovery on customer outcomes. For studies that reported other measures, we converted the other available statistics (e.g., $F$-values or $t$-values) into correlation coefficients using the appropriate formulae (Hunter and Schmidt 
2004; Peterson and Brown 2005). As non-independence of data might potentially bias the metaanalytic results (Bijmolt and Pieters 2001), we included the correlations as independent samples if studies report results from multiple samples. After completing the search process, we had obtained a total of 86 effect sizes from 30 independent samples reported in 21 articles (cumulative $\mathrm{N}=7,872$ ). Two of the authors completed the coding of the moderator variables (see below Appendix 1 for information about the coding procedure). The two coders achieved a high level of consistency; the interjudge reliability score (.86), calculated using Rust and Cooil's (1994) proportional reduction in loss measure, exceeds the recommended .80 threshold. Inconsistencies were resolved through discussion.

\subsection{Effect size integration}

We used Hunter and Schmidt's (2004) random-effects approach to calculate averaged correlations. First, the average correlation $(r)$ is corrected for measurement error in both dependent and independent variables by dividing the correlations by the product of the square root of the respective reliabilities of the two particular constructs $\left(r_{\mathrm{rc}}\right)$. When a study did not report a reliability coefficient or used a single-item measure, we used the mean sample-size weighted reliability for that construct across all studies. Second, we weigh the reliabilitycorrected correlations by the sample size of the study to adjust for sampling error $\left(r_{\text {rcsw }}\right)$, after which we calculate standard errors, $95 \%$ confidence intervals, and significance tests for these reliability-corrected, sample size-weighted correlation. We do not apply a Fisher z transformation when integrating correlations: Fisher $\mathrm{z}$ transformed correlations overestimate the true effect size of heterogeneous correlations with $15 \%$ to $45 \%$ (Field 2001). We examined the homogeneity of the effect size distribution using several tests (i.e., a Chi ${ }^{2}$ test and the $75 \%$ rule-of-thumb; Hunter and Schmidt 2004). We also calculated a file drawer N-statistic for each relationship (Rosenthal 1979), which refers to the number of null studies necessary to bring significant relationships to a $p=.05$ level. 
Finally, we also calculated the statistical power of our meta-analysis, which refers to the probability of correctly rejecting a null hypothesis given that it is false. Significance tests with sufficient levels of statistical power can reliably discriminate between the null hypothesis and alternative hypothesis (Faul et al. 2007). Given the relatively low number of studies included in our meta-analysis, the statistical power analysis can help determine whether the number of studies included in the meta-analysis is sufficient to derive meaningful conclusions (Valentine et al. 2010). The statistical power of a meta-analysis depends on the effect size, the alpha level (.05), the number of studies included in the meta-analysis, and the sample size across these studies. We followed Valentine et al.'s (2010) recommendations to calculate the statistical power of a random-effects meta-analysis.

\subsection{Path model estimation}

In addition to testing the pairwise relationships, we tested the nomological causal model as shown in Figure 1. The model includes eight variables in total; 28 off-diagonal cells need to be filled to create the input correlation matrix for meta-analytic structural equation modeling. Hence, we examined the studies for further statistical information concerning the relationship between the dependent variables. An additional 106 effect sizes were coded and integrated following the aforementioned procedures. We use the harmonic mean of cumulative sample sizes across all relationships as the sample size for the analysis $(\mathrm{N}=1,427)$. Error variances of all variables were set to zero, as measurement errors are already considered when integrating effect sizes. We specified correlations among the three justice dimensions as well as between repurchase intentions and word-of-mouth intentions, as they are related yet distinct constructs (see Gelbrich and Roschk 2011).

\subsection{Moderator analysis}

A multivariate, multilevel meta-regression tests the moderating effects. This model accounts for a nested error structure: articles that report multiple studies with multiple measurements 
cannot be considered as independent from each other (Bijmolt and Pieters 2001). We discern two levels: an effect size level (i.e. correlates of customer participation in service recovery that differ within a study) and a study level (i.e. variables that differ only between studies). As metaregressions typically suffer from a lack of statistical power due to a limited number of observations per relationship and given that we did not propose moderating effects specific to univariate relationships, we analyze the moderators at the multivariate level (e.g., Pick and Eisend 2016; Van Vaerenbergh et al. 2014). We specify the model as follows:

(1) Level 1 model

$$
\begin{aligned}
& E S_{i j}=\beta_{0 j}+\beta_{1 j} \times\left(\text { distributive justice }_{i j}\right)+\beta_{2 j} \times \\
& \left(\text { interactional justice }_{i j}\right)+\beta_{3 j} \times\left(\text { procedural justice }_{i j}\right)+\beta_{4 j} \times \\
& \left(\text { satisfaction with service recovery }_{i j}\right)+\beta_{5 j} \times\left(\text { overall satisfaction }_{i j}\right)+ \\
& \beta_{6 j} \times\left(\text { repurchase intentions }_{i j}\right)+\beta_{7 j} \times(\text { word }- \text { of }- \\
& \text { mouth intentions } \left._{i j}\right)+e_{i j}
\end{aligned}
$$

(2) Level 2 model

$$
\begin{aligned}
& \beta_{0 j}=\gamma_{01} \times\left(\text { type of } \text { failure }_{j}\right)+\gamma_{02} \times \\
& \text { (type of } \text { participation }_{j} \text { : outcome vs.process) }+ \\
& \gamma_{03}\left(\text { type of participation }_{j} \text { : outcome vs. outcome and process }\right)+ \\
& \gamma_{04} \times\left(\text { additional compensation }_{j}\right)+\gamma_{05} \times\left(\text { culture }_{j}\right)+\gamma_{06} \times\left(\text { setting }_{j}\right)+ \\
& \gamma_{07} \times\left(\text { study design }_{j}\right)+\gamma_{08} \times\left(\text { participants }_{j}\right)+\gamma_{09} \times \\
& \left(\text { journal quality }_{j}\right)+u_{0 j}
\end{aligned}
$$

in which $E S S_{\mathrm{ij}}$ is the $\mathrm{i}^{\text {th }}$ reliability-corrected effect size reported within the $\mathrm{j}^{\text {th }}$ sample. Equation 1 describes the effect of different correlates of customer participation in service recovery that vary within studies, equation 2 describes the impact of variables that vary between studies on the intercept of the level 1 equation. $e_{\mathrm{ij}}$ refers to the effect size level residual 
variance, $u_{0 \mathrm{j}}$ refers to the study level residual variance. Because we included a dummy variable for each correlate of customer participation in service recovery at the effect size level, we omitted the intercept (Orsingher et al. 2010). The dummy variables included at the effect size level thus serve as dependent variable-specific intercepts ${ }^{1}$. The multilevel model was estimated using an iterative generalized least squares procedure, which yields maximum likelihood estimates.

\section{RESULTS}

Our analysis proceeds in three steps. First, we provide some descriptive statistics regarding the pairwise relationships between customer participation in service recovery and the outcome variables. Second, we report the results of the path model estimation testing the nomological causal model in Figure 1. Third, we report the results of the moderator analysis.

\subsection{Analysis of pairwise relationships}

Table 1 lists the pairwise relationships between customer participation in service recovery and the outcome variables. $\mathrm{k}$ refers to the number of effect sizes for those particular relationships, $\mathrm{N}$ refers to cumulative sample size of studies examining a certain relationship, $r$ represents the average correlation across the $\mathrm{k}$ studies, $\mathrm{r}_{\mathrm{rc}}$ represents the reliability-corrected correlation across the $\mathrm{k}$ studies, whereas $\mathrm{r}_{\mathrm{rcsw}}$ represents the reliability-corrected sample size-weighted correlation across the $\mathrm{k}$ studies. The results in Table 1 show that customer participation in service recovery is positively and significantly related to distributive justice (.28), satisfaction with service recovery (.20), overall satisfaction (.20), repurchase intentions (.22), and word-ofmouth intentions (.22). Although not significant or marginally significant, the effect sizes of

\footnotetext{
${ }^{1}$ Multilevel meta-regressions often suffer from multicollinearity (e.g. Pick and Eisend 2016). Unfortunately, multilevel models do not offer a direct diagnostic for multicollinearity. Similar to Pick and Eisend (2016), we applied the variables in a linear regression model. The variance inflation factors (maximum VIF=3.0) fall below the recommended threshold, suggesting that multicollinearity is not an issue.
} 
customer participation in service recovery with interactional justice (.20) and procedural justice (.20) are of similar strength than the effect sizes of the other relationships.

[Table 1 here]

The average fail-safe $\mathrm{N}$ exceeds the recommended $5 \mathrm{k}+10$ threshold for all relationships (Rosenthal 1979), which indicates the significant relationships are relatively robust against publication bias. These findings reveal heterogeneity among the observed effect sizes, as the $\chi^{2}$-statistic is significant for all relationships $(p<.001)$ and the sampling error variance to observed variance ratios fall below the recommended 75\% cutoff (Hunter and Schmidt 2004). Finally, the statistical power of the statistical tests largely exceeds the recommended .80 threshold. These findings indicate that our sample size was large enough to derive meaningful implications.

\subsection{Path model results}

Similar to Hong et al. (2013), we evaluated the model fit using the chi square $\left(\chi^{2}\right)$, comparative fit index (CFI), normed fit index (NFI), and standardized root-mean-square residual (SRMR) indices. The model as specified in Figure 1 yields an acceptable fit $\left(\chi^{2}(10)=288.34, p<.001\right.$, $\mathrm{CFI}=97, \mathrm{NFI}=.97, \mathrm{SRMR}=.02)$ and explains $7.3 \%$ of the variance in distributive justice, $3.6 \%$ of interactional justice, $3.6 \%$ of procedural justice, $56.0 \%$ of satisfaction with service recovery, $61.6 \%$ of overall satisfaction, $67.4 \%$ of repurchase intentions, and $75.9 \%$ of wordof-mouth intentions.

Customer participation in service recovery is related to distributive justice (.27), interactional justice (.19) and procedural justice (.19). Distributive justice and procedural justice are related to satisfaction with service recovery (.46 and .33 , respectively), whereas interactional justice is not (.04). Distributive justice and interactional justice are related to overall satisfaction (.21 and .20, respectively), as opposed to procedural justice (.01). Finally, satisfaction with service recovery is related to overall satisfaction (.48), repurchase intentions 
(.05) and word-of-mouth intentions; overall satisfaction is related to repurchase intentions (.48) and word-of-mouth intentions (.71).

We computed Sobel tests for separate assessments of the indirect effects of customer participation in service recovery. Customer participation in service recovery has an indirect effect on satisfaction with service recovery via distributive justice $(.12, p<.001)$ and procedural justice $(.06, p<.001)$, but not via interactional justice $(.01, p=.161)$. Customer participation in service recovery has an indirect effect on overall satisfaction via distributive justice $(.06, p$ $<.001)$ and interactional justice $(.04, p<.001)$, but not via procedural justice $(.00, p=.731)$.

\subsection{Moderator analysis results}

The intraclass correlation coefficient $\rho$ derived from the between-study (.03) and within-study variance (.04) estimates is .52 , indicating that $52 \%$ of the observed variance in effect sizes can be attributed to differences between studies, and that a significant amount of clustering of effect sizes occurred within studies. This observation demonstrates the appropriateness of using a multilevel model for the moderator analysis.

The proposed model explains $49.3 \%$ of the observed variance in effect sizes. The model with level 2 variables provides a significantly better fit than the model only including level 1 variables $\left(\Delta \mathcal{X}^{2}(9)=31.15, p<.001\right)$, demonstrating the additional explanatory power of our moderator variables. Table 2 lists the relevant parameter estimates of the multilevel model ${ }^{2}$. Effect sizes do not differ for outcome and process failures $(\gamma=.08, p>.05)$. Customer participation in the outcome of the recovery produces stronger effects on customer postrecovery evaluations than customer participation in the process of the recovery $(\gamma=-.21, p$ $<.01$ ), yet this effect does not differ from participation in both the process and the outcome of the recovery $(\gamma=.04, p>.05)$. Customer participation in service recovery had a weaker effect

\footnotetext{
${ }^{2}$ We also ran a more parsimonious model, in which we used one intercept rather than the set of dependent variable-specific intercepts at level 1 . The model fit did not change significantly $\left(\Delta \mathcal{X}^{2}(7)=\right.$ $3.511, p>.05$ ). The results for the moderators did not vary substantially.
} 
on customer outcomes when additional compensation was offered $(\gamma=-.19, p<.05)^{3}$ as well as in Western cultures $(\gamma=-.22, p<.05)$. We also found a marginally significant effect of the setting: The effects of customer participation in service recovery on customer outcomes is less strong in online settings as compared to offline settings $(\gamma=-.14, p=.066)$. Regarding the control variables, effect sizes were also less strong in studies using students as participants $(\gamma$ $=-.14, p<.01)$, but stronger in studies published in elite journals $(\gamma=.16, p<.05)$. Effect sizes did not differ between studies using experiments and studies using surveys $(\gamma=.09, p>.05)$.

[Table 2 here]

\section{DISCUSSIONS}

\subsection{Theoretical and managerial implications}

The overall aim of this paper was to consolidate the empirical findings regarding the relationships between customer participation in service recovery and customer outcomes. Our meta-analysis offers the following contributions.

First, this paper outlines the value of involving customers in the recovery to positively influence different customer outcomes (i.e., satisfaction with recovery, overall satisfaction, repurchase and word-of-mouth intentions). Our study complements Gelbrich and Roschk's (2011) meta-analysis, which focused on compensation, favorable employee behavior, and organizational procedures as organizational responses to customer complaints. A careful comparison of our meta-analytic findings with Gelbrich and Roschk's (2011) findings shows that customer participation in service recovery generally leads to markedly weaker effect sizes than the other organizational responses to complaints. One potential explanation for this relatively weaker effect might be that —in line with Herzberg's (1971) two-factor theorycustomers perceive participation in service recovery as a hygiene factor, that is an aspect of the

\footnotetext{
${ }^{3}$ Additional tests show that the strength of this effect does not depend on the nature of the compensation, that is, whether additional monetary compensation or psychological compensation (i.e. an apology) is offered.
} 
service recovery that does not necessarily make customers feel satisfied when it is provided yet might make them feel unhappy when it is not provided. Customers may take participation in service recovery as a requirement, making them less likely to base their post-recovery evaluations based on this aspect.

Second, our conceptual model considers the justice dimensions as intervening variables in the process through which customer participation in service recovery affects the outcome variables (e.g., Gohary et al. 2016; Karande et al. 2007). This meta-analysis shows customer participation in service recovery relates to satisfaction with service recovery through both distributive and procedural justice, and to overall satisfaction via distributive and interactional justice. Altogether, our findings show that distributive justice is of particular importance to explain the customer participation in service recovery-customer outcomes relationships. These findings signal that customers consider customer participation in service recovery not only as a fair procedure (procedural justice), as some authors expect (e.g. Karande et al. 2007), but also as a token of fair interpersonal treatment (interactional justice), and even a fair redress (distributive justice).

Third, we provide insights into the mixed findings reported in literature. Addressing the recent call for more research on the impact of customer participation over different service (recovery) stages (Dong and Sivakumar 2017), our moderator analysis reveals stronger effect sizes when customers participate in the recovery outcome (i.e. having a say in the final decision) compared to when they only participate in the recovery process. Practitioners are recommended to involve customers in the choice of the recovery outcome, rather than just in the recovery process. Moreover, the effect of customer participation in service recovery on customer evaluation decreases when other compensation is offered. This observation reinforces the notion that customers might consider participation in service recovery as a requirement that might increase their satisfaction and behavioral intentions when it is provided during the 
service recovery in case other recovery options are offered. Managers should carefully combine their organizational responses to customer complaints.

Our results also suggest that inviting customers to participate in the recovery process is more recommended in an offline (versus online) setting and is more recommended for companies operating in Eastern than in Western cultures. Xu et al. (2014) show Eastern (versus Western) customers attach more importance to the employee initiating the co-recovery; we complement these findings by showing Eastern customers attach more importance to participating in the recovery in general. Overall, these findings offer useful insights to managers about when customer participation in service recovery is recommended.

Finally, our study shows that researchers should be cautious in interpreting and generalizing findings from studies using student samples or reported in elite journals as it might lead to an overestimation of the average effect size. To summarize, this paper provides significant insights into why the literature reports mixed findings across studies.

\subsection{Limitations and suggestions for future research}

This meta-analysis suffers from some intrinsic limitations. First, this study only addresses those constructs for which sufficient primary data were available. For instance, our model does not include perceived failure severity, nor customers' level of participation in failed encounters among the moderators, as these variables were only addressed in a few studies (e.g., Roggeveen et al. 2012). While such omitted variables may produce a potential bias, our framework should be considered as a summary of the most common variables investigated in the literature. Second, though our theoretical model is largely validated, it only explains a limited portion of variance in both the justice dimensions and customer outcomes (e.g., 56\% of satisfaction with service recovery). We corroborate with Van Vaerenbergh and Orsingher's (2016) call for more research investigating other mediators than justice to better understand the effects of firm recovery actions on customer outcomes. 


\section{REFERENCES}

References marked with an asterisk are included in the meta-analysis:

*Armirotto, V. (2016) How can we best solve your problem? The impact of co-creation of service recovery on complaining customers' perceptions. Master thesis: KU Leuven, Belgium.

Association of Business Schools (2015) Academic Journal Guide 2015. 54 pages.

*Balaji, M. S., Jha, S., Sengupta, A. S., Krishnan, B. C. (2018) Are cynical customers satisfied differently? Role of negative inferred motive and customer participation in service recovery. J Bus Res, 86:109-118.

Bijmolt, T. H. A., Pieters, R. G. M. (2001) Meta-analysis in marketing when studies contain multiple measurements. Mark Lett, 12:157-169.

Burnett, J. J., Dune, P. M. (1986) An Appraisal of the Use of Student Subjects in Marketing Research. J Bus Res, 14:329-343.

Chan, H., Wan, L.C., Sin, L.Y.M. (2007). Hospitality service failures: Who will be more dissatisfied? Int J Hosp Manag, 26:531-545

Chang, C.-C., Chin, Y.-C. (2011) Comparing consumer complaint responses to online and offline environment. Internet Res, 21:124-137.

*Cheung, F. Y. M., To, C. W. M. (2016). A customer-dominant logic on service recovery and customer satisfaction ", Manag Dec, 54:2524-2543.

*Collier, J. E., Breazeale, M., White, A. (2017) Giving back the "self” in self-service: Customer preferences in self-service failure recovery. J Serv Mark, 31:604-617.

*Dong, B., Evans, K. R., Zou, S. (2008) The effects of customer participation in co-created service recovery. J Acad Mark Sci, 36:123-137. 
*Dong, B., Sivakumar, K., Evans, K. R., Zou, S. (2016) Recovering coproduced service failures: Antecedents, consequences, and moderators of locus of recovery. J Serv Res, 19: 291-306.

Dong, B., Sivakumar, K. (2017) Customer participation in services: domain, scope, and boundaries. J Acad Mark Sci, 45:944-965.

Farley, J. U., Lehmann, D. R., Sawyer, A. (1995) Empirical Marketing Generalization Using Meta-Analysis. Mark Sci, 14:36-46.

Faul, F., Erdfelder, E., Lang, A.-G., Buchner, A. (2007) G*Power 3: A flexible statistical power analysis for the social, behavioral, and biomedical sciences. Beh Res Meth, 39:175-191.

Field, A. (2001) Meta-analysis of correlation coefficients: A Monte Carlo comparison of fixed- and random-effects methods. Psych Meth, 6:161-180.

Gelbrich, K., Roschk, H. (2011) A meta-analysis of organizational complaint handling and customer responses. J Serv Res, 14:24-43.

*Gohary, A., Hamzelu, B., Alizadeh, H. (2016a) Please explain why it happened! How perceived justice and customer involvement affect post co-recovery evaluations: A study of Iranian online shoppers. J Retailing Consum Serv, 31:127-142.

*Gohary, A., Hamzelu, B., Pourazizi, L., Hanzaee, K. H. (2016b) Understanding effects of co-creation on cognitive, affective and behavioral evaluations in service recovery: An ethnocultural analysis. J Retailing Consum Serv, 31:182-198.

Grönroos, C. (1988) Service quality: The six criteria of good perceived service quality. Rev Bus, 9:10-13.

*Guo, L., Lotz, S. L., Tang, C., Gruen, T. W. (2016) The role of perceived control in customer value cocreation and service recovery evaluation. $J$ Serv Res, 19:39-56. 
*Hazée, S., Van Vaerenbergh, Y., Armirotto, V. (2017) Co-creating service recovery after service failure: The role of brand equity. J Bus Res, 75:101-109.

*Heidenreich, S., Wittkowski, K., Handrich, M., Falk, T. (2015) The dark side of customer co-creation: Exploring the consequences of failed co-created services. $J$ Acad Mark Sci, 43:279-296.

Herzberg, F. (1971) Work and the nature of man. New York: World Publishing.

Hofstede, G. (1997) Cultures and organizations: Software of the mind. London: McGrawHill.

Hong, Y., Liao, H., Hu, J., Jiang, K. (2014) Missing link in the service profit chain: A metaanalytic review of the antecedents, consequences, and moderators of service climate. $J$ Appl Psych, 98:237-267.

*Huang, H-H. (2016) A study of customer co-recovery from self-oriented and other-oriented perspectives. J Hosp Leis Sport To, 6:1-28.

*Huang, H-H., Wang, J. S., Kung, S. H. (2016) The influence of customer participation in service recovery on overall satisfaction and repurchase intention. J Nat Huwei Uni Sci Tech, 33:1-11.

Hunter, J. E., Schmidt, F. L. (2007) Methods of meta-analysis: Correcting error and bias in research findings (2 ${ }^{\text {nd }}$ ed.). Thousand Oaks, CA: Sage.

Joireman, J., Grégoire, Y., Devezer, B., Tripp, T.M. (2013) When do customers offer firms a "second chance" following a double deviation? The impact of inferred firm motives on customer revenge and reconciliation. J Retail, 89:315-337.

*Joosten, H., Bloemer, J., Hillebrand, B. (2017) Consumer control in service recovery: beyond decisional control. J Serv Manag, 28:499-519. 
*Karande, K., Magnini, V.P., Tam, L. (2007) Recovery voice and satisfaction after service failure: An experimental investigation of mediating and moderating factors. J Serv Res, $10: 187-203$.

Knox, G., Van Oest, R. (2014) Customer complaints and recovery effectiveness: A customer base approach. $J$ Mark, 78:42-57.

*Mattila, A. S. (2010) Do women like options more than men? An examination in the context of service recovery. J Serv Mark, 24:499-508;

Murtaugh, P. A. (2002) Journal quality, effect size, and publication bias in meta-analysis. Ecol, 83:1162-1166.

Orsingher, C., Valentini, S., de Angelis, M. (2010) A meta-analysis of customer satisfaction with complaint handling in services. J Acad Mark Sci, 38:169-186.

Payne, A.F., Storbacka, K., Frow, P. (2008). Managing the co-creation of value. J Acad Mark Sci, 36:83-96.

Peterson, R. A., Brown, S. P. (2005) On the use of beta coefficients in meta-analysis. J Appl Psych, 90:175-181.

Peterson, R. A., Merunka, D.R. (2014) Convenience samples of college students and research reproducibility. J Bus Res, 67:1035-1041.

Pick, D., Eisend, M. (2016) Customer responses to switching costs: A meta-analytic investigation of the moderating influence of culture. $J$ Int Mark, 24:39-60.

*Roggeveen, A. L., Tsiros, M., Grewal, D. (2012) Understanding the co-creation effect: when does collaborating with customers provide a lift to service recovery? J Acad Mark Sci, 40:771-790.

Rosenthal, R. (1979) The 'file-drawer problem' and tolerance for null results. Psych Bull, 86:638-641. 
Rust, R., Cooil, B. (1994) Reliability measures for qualitative data: Theory and implications. J Mark Res, 31:1-14.

Rust, R., Lemon, K. (2001) E-service and the consumer. Int J Electron Comm, 5:85-101.

Sengupta, S., Ray, D., Trendel, O., Van Vaerenbergh, Y. (2018). The effect of apologies in the global online retail. Int J Electron Comm, 22:419-445.

Sharma, P. (2010) Measuring personal cultural orientations: Scale development and validation. J Acad Mark Sci, 38:787-806.

Smith, A. K., Bolton, R. N., Wagner, J. (1999) A model of customer satisfaction with service encounter involving failure and recovery. J Mark Res, 36:356-372.

*Talgø, T., Rødsjø, E. L. (2017) You break it, you fix it? Customer participation in service production and service recovery. Master thesis: BI Norwegian Business School, Norway.

Valentine, J.C., Pigott, T.D., Rothstein, H.R. (2010) How many studies do you need? A primer on statistical power for meta-analysis. J Educ Beh Stat, 35:215-247.

Van Vaerenbergh, Y., Orsingher, C. (2016) Service recovery: An integrative framework and research agenda. Acad Manag Perspect, 30:328-346.

Van Vaerenbergh, Y., Orsingher, C., Vermeir, I., Larivière, B. (2014). A meta-analysis of relationships linking service failure attributions to customer outcomes. J Serv Res, 17:381-398.

Vargo, S. L., Lusch, R. F. (2016) Institutions and axioms: An extension and update of service-dominant logic. J Acad Mark Sci, 44:5-23.

*Vazquez-Casielles, R., Iglesias, V., Varela-Neira, C. (2017) Co-creation and service recovery process communication: effects on satisfaction, repurchase intentions, and word of mouth. Serv Bus, 11:321-343.

Völckner, F., Hofmann, J. (2007) The price-perceived quality relationship: A meta-analytic review and assessment of its determinants. Mark Lett, 18:181-196. 
*Xu, Y., Tronvoll, B., Edvardsson, B. (2014a) Recovering service failure through resource integration. Serv Ind J, 34:1253-1271.

*Xu, Y., Marshall, R., Edvardsson, B., Tronvoll, B. (2014b) Show you care: Initiation cocreation in service recovery. J Serv Manag, 25:369-387. 
Appendix 1: Overview of studies used in the meta-analysis

\begin{tabular}{|c|c|c|c|c|c|c|c|c|c|}
\hline Study & $\begin{array}{l}\text { Type of } \\
\text { failure }^{\mathrm{a}}\end{array}$ & $\begin{array}{c}\text { Type of } \\
\text { participation }^{b}\end{array}$ & $\begin{array}{c}\text { Additional } \\
\text { compensation }^{c}\end{array}$ & $\begin{array}{c}\text { Study } \\
\text { context }\end{array}$ & Culture $^{d}$ & $\begin{array}{l}\text { Study } \\
\text { design }\end{array}$ & Sample & $\begin{array}{l}\text { Journal } \\
\text { quality }\end{array}$ & $\begin{array}{c}\text { Sample } \\
\text { size }^{\text {f }}\end{array}$ \\
\hline Armirotto (2016) & Outcome & Process & Yes & Offline & Western & Experiment & Student & Non-elite & 120 \\
\hline Balaji et al. (2018, study 2) & Outcome & Process & Yes & Offline & Western & Experiment & Non-students & Non-elite & 122 \\
\hline Cheung and To (2016) & Process & Process & No & Offline & Eastern & Survey & Non-students & Non-elite & 594 \\
\hline Collier et al. (2017, study 1$)$ & Process & Process & No & Offline & Eastern & Experiment & Student & Non-elite & 158 \\
\hline Collier et al. (2017, study 2) & Process & Process & No & Offline & Eastern & Experiment & Student & Non-elite & 150 \\
\hline Collier et al. (2017, study 3$)$ & Process & Process & No & Offline & Eastern & Experiment & Non-students & Non-elite & 175 \\
\hline Dong et al. (2008) & Process & Process & No & Online & Western & Experiment & Student & Elite & 223 \\
\hline Dong et al. (2016, study 2) & Process & Process & No & Online & Western & Experiment & Student & Elite & 92 \\
\hline Dong et al. (2016, study 3 ) & Process & Process & No & Online & Western & Experiment & Non-students & Elite & 439 \\
\hline Gohary et al. (2016a) & Process & Process & Yes & Online & Eastern & Experiment & Non-students & Non-elite & 278 \\
\hline Gohary et al. (2016b) & Outcome & Process & Yes & Online & Eastern & Experiment & Non-students & Non-elite & 944 \\
\hline Guo et al. (2016, study 1) & Both $^{\mathrm{g}}$ & Both & No & Offline & Western & Survey & Non-students & Elite & 283 \\
\hline Hazée et al. (2017, sample 1) & Outcome & Process & Yes & Offline & Western & Experiment & Non-students & Non-elite & 464 \\
\hline Hazée et al. (2017, sample 2) & Outcome & Process & Yes & Offline & Western & Experiment & Non-students & Non-elite & 466 \\
\hline Heidenreich et al. (2015, study 3 ) & Process & Process & Yes & Online & Western & Experiment & Non-students & Elite & 338 \\
\hline Heidenreich et al. (2015, study 4) & Outcome & Both & Yes & Offline & Western & Experiment & Non-students & Elite & 265 \\
\hline Huang (2016) & Outcome & Outcome & Yes & Offline & Eastern & Experiment & Student & Non-elite & 60 \\
\hline Huang et al. (2016) & Outcome & Outcome & Yes & Offline & Eastern & Experiment & Student & Non-elite & 120 \\
\hline Joosten et al. (2017) & Outcome & Both & No & Offline & Eastern & Survey & Non-students & Non-elite & 260 \\
\hline Karande et al. (2007, sample 1) & Outcome & Outcome & Yes & Offline & Western & Experiment & Non-students & Elite & 216 \\
\hline Karande et al. (2007, sample 2) & Outcome & Outcome & Yes & Offline & Western & Experiment & Non-students & Elite & 208 \\
\hline Mattila (2010) & Outcome & Outcome & Yes & Offline & Western & Experiment & Non-students & Non-elite & 195 \\
\hline Roggeveen et al. (2012, study 1) & Outcome & Process & Yes & Offline & Western & Experiment & Student & Elite & 79 \\
\hline Roggeveen et al. (2012, study 2) & Outcome & Process & Yes & Offline & Western & Experiment & Student & Elite & 111 \\
\hline Roggeveen et al. (2012, study 3) & Outcome & Process & Yes & Offline & Western & Experiment & Student & Elite & 87 \\
\hline Talgø and Rødsjø (2011) & Outcome & Process & No & Offline & Western & Experiment & Student & Non-elite & 240 \\
\hline Vazquez et al. (2017, sample 1$)$ & Process & Process & Yes & Offline & Western & Experiment & Non-students & Non-elite & 240 \\
\hline Vazquez et al. (2017, sample 2) & Process & Process & Yes & Offline & Western & Experiment & Non-students & Non-elite & 240 \\
\hline $\mathrm{Xu}$ et al. (2014a) & Outcome & Both & No & Offline & Eastern & Experiment & Student & Non-elite & 287 \\
\hline Xu et al. $(2014 b)$ & Outcome & Outcome & Yes & Offline & Western & Experiment & Student & Non-elite & 418 \\
\hline
\end{tabular}

Notes: ${ }^{a}$ Services failures were coded according to Smith et al.'s (1999) classification (outcome or process failure). 
${ }^{\mathrm{b}}$ Service recovery participation was similarly coded (participation in the outcome or process recovery).

"Additional compensation was coded as "Yes" if additional monetary and/or psychological compensation was offered by the service provider.

${ }^{\mathrm{d}}$ Belgium, Germany, Spain, and the United States were classified as Western countries, whereas Hong Kong, Iran, and Taiwan were coded as Eastern countries. In case of studies in multiple countries (e.g. Xu et al., 2014b), classification was upon the location the majority of respondents came from.

${ }^{\mathrm{e}}$ Elite and non-elite journals were differentiated based on the Association for Business School (ABS) Journal Ranking list; journals receiving at least a 4 on the ABS list (in our sample: Journal of the Academy of Marketing Science and Journal of Service Research) were classified as elite journals.

${ }^{\mathrm{f}}$ Sample sizes reported in this table might differ from the overall sample size reported in the paper. For example, Huang et al.'s, (2016) study manipulates customer participation in service recovery in two out of three experimental conditions. We use the sample size for those two cells rather than the total sample size.

${ }^{\mathrm{g}}$ Given that only one study was coded as focusing on both process and outcome failures, this value was not included in the moderator analysis. 
Figure 1: Meta-analytic framework

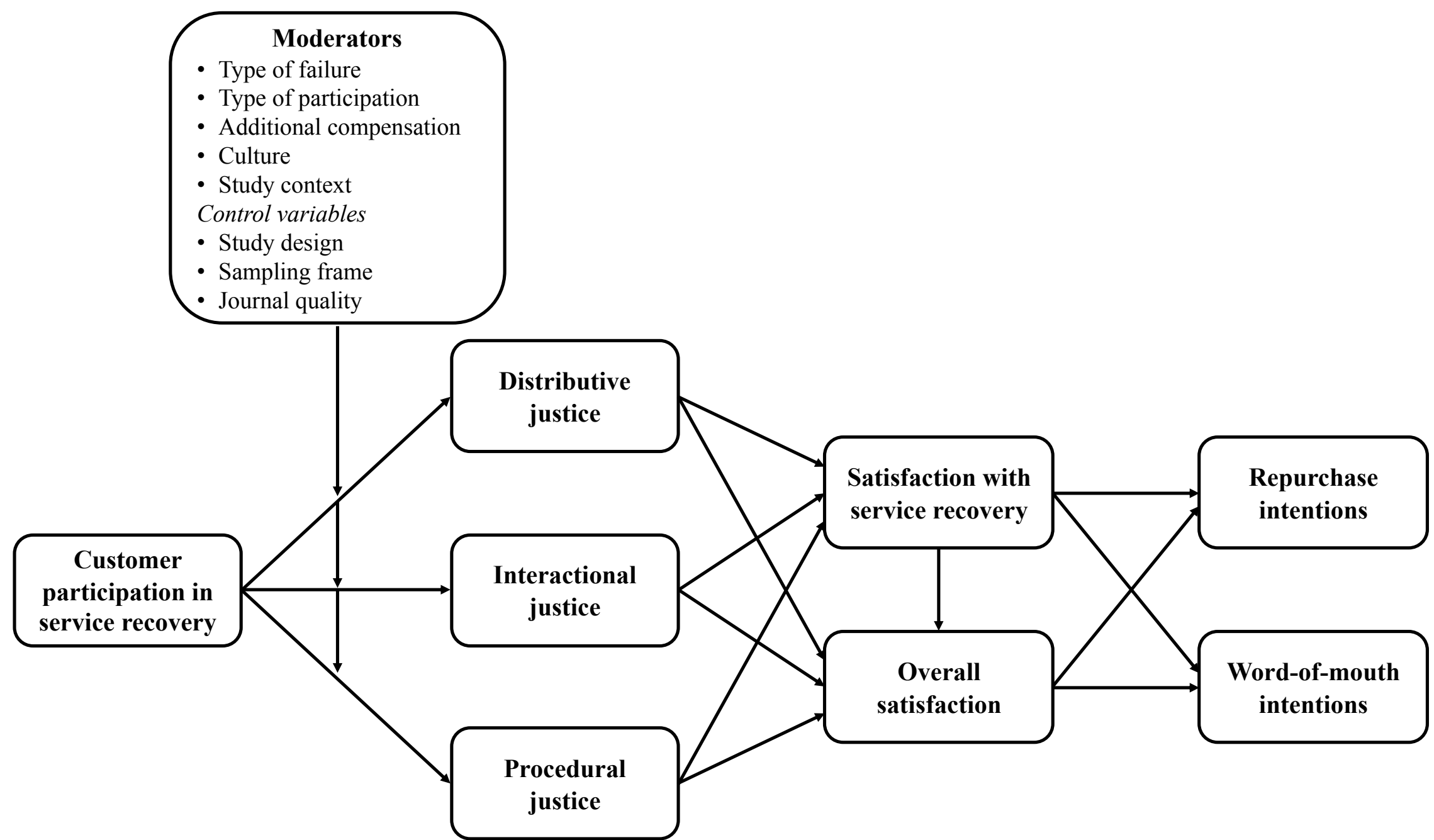

Note: Causal ordering of the outcome variables is in line with Gelbrich and Roschk (2011). 
Table 1: Analysis of pairwise relationships

95\% File-

confidence drawer Chi2 test of $75 \%$

\begin{tabular}{|c|c|c|c|c|c|c|c|c|c|c|c|}
\hline & Relationships & $\mathrm{k}$ & $\mathrm{N}$ & $\mathrm{r}$ & $\mathrm{r}_{\mathrm{rc}}$ & $\mathrm{r}_{\mathrm{rcsw}}$ & intervals & $\mathrm{N}$ & homogeneity & rule & Power \\
\hline \multirow{7}{*}{ 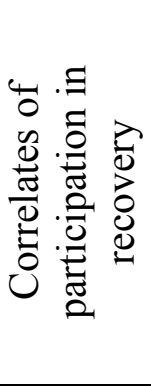 } & CPSR-DJ & 8 & 2,834 & .25 & .27 & .28 & $.06 \mid .49$ & 929 & $259,29 * * *$ & $3 \%$ & $>.99$ \\
\hline & CPSR-IJ & 7 & 2,594 & .17 & .19 & .20 & $-.06 \mid .46$ & - & $283,73 * * *$ & $2 \%$ & $>.99$ \\
\hline & CPSR-PJ & 8 & 2,731 & .18 & .19 & .20 & $.00 \mid .40$ & 644 & $209,86^{* * *}$ & $4 \%$ & $>.99$ \\
\hline & CPSR-SATSR & 20 & 5,884 & .18 & .19 & .20 & $.09 \mid .30$ & 2,121 & $310,53 * * *$ & $6 \%$ & $>.99$ \\
\hline & CPSR-OSAT & 14 & 3,199 & .18 & .20 & .20 & $.11 \mid .30$ & 660 & $96,12 * * *$ & $15 \%$ & $>.99$ \\
\hline & CPSR-RI & 20 & 5,513 & .20 & .22 & .22 & $.13 \mid .31$ & 1,422 & $207,7 * * *$ & $10 \%$ & $>.99$ \\
\hline & CPSR-WOM & 9 & 2,376 & .18 & .19 & .22 & $.05 \mid .38$ & 262 & $145,58 * * *$ & $6 \%$ & $>.99$ \\
\hline \multirow{21}{*}{ 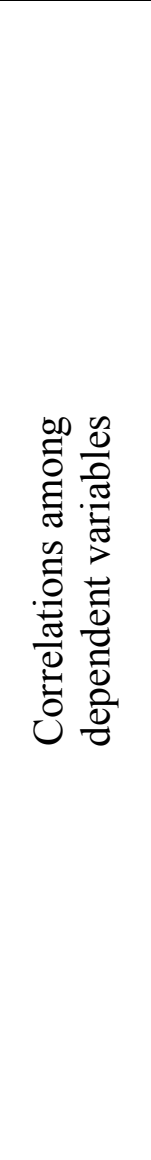 } & DJ-IJ & 6 & 2,483 & .58 & .63 & .63 & $.49 \mid .77$ & 2,196 & $181,91 * * *$ & $3 \%$ & $>.99$ \\
\hline & DJ-PJ & 5 & 2,196 & .62 & .66 & .51 & $.23 \mid .79$ & 1,524 & $299,03 * * *$ & $2 \%$ & $>.99$ \\
\hline & DJ-SATSR & 7 & 2,723 & .63 & .70 & .64 & $.50 \mid .78$ & 3,239 & $219,61 * * *$ & $3 \%$ & $>.99$ \\
\hline & DJ-OSAT & 3 & 620 & .60 & .67 & .67 & $.59 \mid .75$ & 301 & $25,48 * * *$ & $12 \%$ & $>.99$ \\
\hline & DJ-RI & 5 & 1,842 & .56 & .60 & .56 & $.46 \mid .66$ & 1,071 & $53,66 * * *$ & $9 \%$ & $>.99$ \\
\hline & DJ-WOM & 3 & 658 & .64 & .67 & .68 & $.63 \mid .74$ & 378 & $8,65^{* *}$ & $35 \%$ & $>.99$ \\
\hline & IJ-PJ & 5 & 2,196 & .72 & .77 & .73 & $.63 \mid .82$ & 2,578 & $115,69 * * *$ & $4 \%$ & $>.99$ \\
\hline & IJ-SATSR & 6 & 2,483 & .54 & .58 & .60 & $.34 \mid .86$ & 2,597 & $590,62 * * *$ & $1 \%$ & $>.99$ \\
\hline & IJ-OSAT & 2 & 380 & .57 & .61 & .66 & $.48 \mid .84$ & 119 & $20,24 * * *$ & $10 \%$ & $>.99$ \\
\hline & IJ-RI & 4 & 1,602 & .52 & .56 & .68 & $.44 \mid .93$ & 875 & $216,82 * * *$ & $2 \%$ & $>.99$ \\
\hline & IJ-WOM & 3 & 658 & .49 & .51 & .52 & $.31 \mid .73$ & 203 & $42,21 * * *$ & $7 \%$ & $>.99$ \\
\hline & PJ-SATSR & 5 & 2,196 & .62 & .65 & .54 & $.25 \mid .82$ & 1,674 & $358,41 * * *$ & $1 \%$ & $>.99$ \\
\hline & PJ-OSAT & 4 & 804 & .57 & .61 & .63 & $.56 \mid .70$ & 472 & $14,68 * *$ & $27 \%$ & $>.99$ \\
\hline & PJ-RI & 4 & 1,602 & .54 & .57 & .49 & $.29 \mid .69$ & 657 & $97,64 * * *$ & $4 \%$ & $>.99$ \\
\hline & PJ-WOM & 3 & 658 & .61 & .64 & .70 & $.51 \mid .88$ & 399 & $59,21 * * *$ & $5 \%$ & $>.99$ \\
\hline & SATSR-OSAT & 5 & 1,550 & .66 & .74 & .82 & $.64 \mid 1.0$ & 1,952 & $543,12 * * *$ & $1 \%$ & $>.99$ \\
\hline & SATSR-RI & 11 & 3,976 & .59 & .63 & .64 & $.57 \mid .72$ & 6,679 & $212,41^{* * *}$ & $5 \%$ & $>.99$ \\
\hline & SATSR-WOM & 5 & 1,588 & .70 & .73 & .77 & $.69 \mid .85$ & 2,086 & $69,21 * * *$ & $7 \%$ & $>.99$ \\
\hline & OSAT-RI & 7 & 2,030 & .75 & .82 & .84 & $.76 \mid .92$ & 4,300 & $234,58 * * *$ & $3 \%$ & $>.99$ \\
\hline & OSAT-WOM & 6 & 1,790 & .79 & .86 & .86 & $.83 \mid .90$ & 3,626 & $171,1 * * *$ & $4 \%$ & $>.99$ \\
\hline & RI-WOM & 7 & 2,068 & .79 & .82 & .84 & $.78 \mid .90$ & 5,370 & $135,37 * * *$ & $5 \%$ & $>.99$ \\
\hline
\end{tabular}

Notes: ${ }^{* * *} p<.001,{ }^{* *} p<.01, * p<.05$, ${ }^{\text {n.s. }}$ not significant, $\mathrm{CPSR}=$ customer participation in service recovery, $\mathrm{DJ}=$ distributive justice, $\mathrm{IJ}=$ interactional justice, $\mathrm{PJ}=$ procedural justice, $\mathrm{SATSR}=$ satisfaction with service recovery, OSAT= overall satisfaction, $\mathrm{RI}=$ repurchase intentions, $\mathrm{WOM}=$ word-of-mouth intentions; $\mathrm{k}=$ number of effect sizes, $\mathrm{N}=$ cumulative sample size, $\mathrm{r}=$ average correlation, $\mathrm{r}_{\mathrm{rc}}=$ reliability-corrected correlation, $\mathrm{r}_{\mathrm{rcsw}}=$ reliability-corrected sample size-weighted correlation. 
Table 2: Moderator analysis results

\begin{tabular}{|c|c|c|c|}
\hline Variables & $\begin{array}{c}\text { Parameter } \\
\text { estimate }\end{array}$ & $\begin{array}{c}\text { Standard } \\
\text { error }\end{array}$ & $p$-value \\
\hline \multicolumn{4}{|l|}{ Level 1 variables } \\
\hline Distributive justice $(0=$ No, $1=$ Yes $)$ & .68 & .14 & $<.001$ \\
\hline Interactional justice $(0=$ No, $1=$ Yes $)$ & .57 & .15 & $<.001$ \\
\hline Procedural justice $(0=$ No, $1=$ Yes $)$ & .56 & .13 & $<.001$ \\
\hline Satisfaction with service recovery $(0=$ No, $1=$ Yes $)$ & .67 & .13 & $<.001$ \\
\hline Overall satisfaction $(0=$ No, $1=$ Yes $)$ & .65 & .12 & $<.001$ \\
\hline Repurchase intentions $(0=$ No, $1=$ Yes $)$ & .66 & .12 & $<.001$ \\
\hline Word-of-mouth intentions $(0=\mathrm{No}, 1=\mathrm{Yes})$ & .67 & .13 & $<.001$ \\
\hline \multicolumn{4}{|l|}{ Level 2 variables } \\
\hline Type of failure $(0=$ Outcome failure, $1=$ Process failure $)$ & .08 & .07 & .281 \\
\hline Type of participation $(0=$ Outcome, $1=$ Process $)$ & -.21 & .08 & .008 \\
\hline Type of participation $(0=$ Outcome, $1=$ Outcome $\&$ Process $)$ & .04 & .14 & .753 \\
\hline Additional compensation $(0=$ No, $1=$ Yes $)$ & -.19 & .07 & .011 \\
\hline Culture $(0=$ Eastern, $1=$ Western $)$ & -.22 & .08 & .012 \\
\hline Setting $(0=$ Offline, $1=$ Online $)$ & -.14 & .08 & .066 \\
\hline \multicolumn{4}{|l|}{ Level 2 control variables } \\
\hline Study design $(0=$ Experiment, $1=$ Survey $)$ & .09 & .10 & .363 \\
\hline Participants $(0=$ Nonstudents, $1=$ Students $)$ & -.13 & .06 & .015 \\
\hline Journal quality $(0=$ Non-elite, $1=$ Elite $)$ & .16 & .07 & .018 \\
\hline
\end{tabular}

Notes: Unstandardized regression coefficients are reported. Level 1 variables represent customer outcomespecific intercepts. 